\title{
Role of Blood Volume in the Age-Associated Decline in Peak Oxygen Uptake in Humans
}

\author{
Tomoyuki ITO, Akira TAKAMATA, Kazuhiro YAEGASHI, Toshiyuki ITOH, Tetsuya YOSHIDA, \\ Takashi KAWABATA, Misaka KIMURA, and Taketoshi MORIMOTO
}

Department of Physiology, Kyoto Prefectural University of Medicine, Kyoto, 602-0841 Japan

\begin{abstract}
It has been reported that maximal oxygen uptake $\left(\dot{V}_{2}\right.$ max $)$ is linearly correlated with blood volume (BV) in young people and that there is a reduction in $\dot{V O}_{2 \max }$ with aging. To examine the involvement of $\mathrm{BV}$ in the reduction of $\dot{V} \mathrm{O}_{2 \max }$, we used an incremental cycle ergometer protocol in a semirecumbent position to determine the relationship between peak oxygen up-

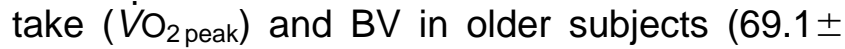
1.0 years; $n=22$ ), then compared that relationship with that in young subjects $(22.3 \pm 0.5$ years; $n=31)$. In the present study, $\dot{V}_{2 \text { peak }}$ and BV were significantly lower in the older subjects, compared with those in the young subjects. A linear correlation was demonstrated between the $\dot{V}_{2 \text { peak }}$ and $\mathrm{BV}$ in both the older $(r=0.705 ; p<$ $0.001)$ and the young $(r=0.681 ; p<0.001)$ sub-
\end{abstract}

jects within the groups. However, an analysis of covariance with $\mathrm{BV}$ as a covariate revealed that $\dot{V} \mathrm{O}_{2 \text { peak }}$ at a given $\mathrm{BV}$ was smaller in the older subjects than in the young subjects $(p<0.001)$, i.e., graphically, the regression line determined for the older subjects showed a downward shift. The decreased peak heart rate as a result of aging $(153 \pm 3$ beats $/ \mathrm{min}$ in the older vs. $189 \pm 2$ beats/min in the young subjects) contributed partly to this downward shift. These results suggest that the BV is an important determinant factor for $\dot{V} \mathrm{O}_{2 \text { peak }}$, especially within an age group, and that the age-associated decline of $\dot{V}_{2}$ peak is also, to a relatively larger degree, because of factors other than BV and heart rate. [Japanese Journal of Physiology, 51, 607-612, 2001]

Key words: aging, maximal aerobic power, Frank-Starling mechanism.

$\mathrm{P}_{\mathrm{h}}$ though the rate of decline varies among the functional systems [1]. A decline in maximal oxygen uptake $\left(\dot{V} \mathrm{O}_{2 \max }\right)$ with aging has been reported in cross-sectional and longitudinal studies [2-6]. It is thought that the causes of $\dot{V}_{2}$ max reduction with aging are related to the attenuation of a variety of functional systems. But the mechanism of the reduction in $\dot{V}_{2}$ max with aging remains poorly understood [1].

Blood volume (BV) is an important determinant of cardiovascular function, and it also has an influence on aerobic exercise capacity [7-10]. It has been reported that $\dot{V} \mathrm{O}_{2 \max }$ is linearly correlated with $\mathrm{BV}$ in younger subjects [7-10]. Physical training increases $\dot{V} \mathrm{O}_{2 \max }$ and also $\mathrm{BV}$ [7], and the reduction of $\dot{V} \mathrm{O}_{2 \max }$ induced by a long-term bed rest regimen is accompa- nied with a reduction in BV [11]. Furthermore, several studies have shown that an acute $\mathrm{BV}$ or plasma volume expansion increases $\dot{V} \mathrm{O}_{2 \text { max }}$, with an increase in cardiac stroke volume during exercise [12, 13]. Thus the change in $\dot{V}_{2}$ max with the alteration of $\mathrm{BV}$ is quite likely a result of the change in cardiac stroke volume according to the Frank-Starling mechanism.

The fraction of total body fluid decreases with aging [14], and several studies have reported that BV was smaller in older than in younger individuals [8-10]. Stevenson et al. [15] reported that $\dot{V}_{2}$ max was linearly correlated with BV in middle-aged and older female athletes, suggesting that the linear relationship between $\dot{V}_{2}$ max and $\mathrm{BV}$ is preserved in relatively older adults. Jones et al. [10] reported that BV was maintained in physically active older women and that

Received on February 7, 2001; accepted on August 10, 2001

Correspondence should be addressed to: Akira Takamata, Department of Physiology, Kyoto Prefectural University of Medicine, Kamigyoku, Kyoto, 602-0841 Japan. Tel: +81-75-251-5311, Fax: +81-75-251-0295, E-mail: akira@basic.kpu-m.ac.jp 
the $\mathrm{BV}-\dot{\mathrm{O}}_{2 \max }$ relationship was not influenced by aging. However, that is the only study in which the relationship between $\dot{V}_{2}$ max and $\mathrm{BV}$ in older and younger adults was compared, and the fitness level of those women was relatively high. Not enough data is available on the age-associated change in the relationship between $\dot{V}_{\mathrm{O}_{2} \max }$ and $\mathrm{BV}$. A comparison of this relationship in young and older adults would provide important information on the mechanism of the ageassociated decline in $\dot{V}_{2}$ max .

To elucidate the role of $\mathrm{BV}$ in the age-associated decrease in $\dot{V}_{2}$ max , in the present study we determined the relationship between peak oxygen uptake $\left(\dot{V}_{\mathrm{O}_{2 \text { peak }}}\right)$, measured with an incremental cycling exercise protocol in a semirecumbent position, and $\mathrm{BV}$ in relatively sedentary older subjects (58-80 years, and 19 of the 22 subjects were older than 65), and compared these findings with those obtained from young subjects. If the primary factor of the age-associated decline in $\dot{V}_{2}$ peak is the reduction in $\mathrm{BV}$, it should be possible to apply a single regression equation to the data obtained from older and younger subjects.

\section{METHOD}

Subjects. Twenty-two older subjects (12 males and 10 females) and 31 younger subjects (20 male and 11 females) participated in this study. Because the number of older subjects of a single gender available for this study was limited, we included the subjects of both the male and the female subjects in this study. Eight of the 22 older subjects were relatively active; they tried to take walks daily, but they were not engaged in any intense exercise training program. The remaining 14 older subjects were sedentary. Twentythree of the 31 younger subjects performed in some form of exercise 3 or more days a week, and the remaining 8 were sedentary. The physical characteristics of the subjects are shown in Table 1. The range of age in the older subjects was 58-80 years, and 19 of 22 were older than 65 . The range of age in the younger subjects was $18-28$. A complete medical history and physical examination, including a 12-lead electrocardiogram, showed that all subjects were in good health. Written informed consent was obtained from each one before participation in the study. This study was approved by the Review Board on Human Experiments, Kyoto Prefectural University of Medicine.

Protocol and measurements. Subjects refrained from taking any food for at least $8 \mathrm{~h}$ before reporting to the laboratory. We determined the $\mathrm{BV}$ and $\dot{V}_{\mathrm{O}_{2 \text { peak }}}$ for each subject on the same day.

BV was determined by the Evans Blue dye dilution technique. For the younger female subjects, we determined the BV on a day other than those days on or around the expected ovulation day, because it has been reported that $\mathrm{BV}$ is higher on an ovulation day in comparison with others [16]. The subjects sat on

Table 1. Physical characteristics of the subjects.

\begin{tabular}{|c|c|c|c|c|}
\hline & \multicolumn{2}{|c|}{ Older } & \multicolumn{2}{|c|}{ Younger } \\
\hline & Male & Female & Male & Female \\
\hline \multirow{2}{*}{ Age (years) } & \multicolumn{2}{|c|}{$69.1 \pm 1.0$} & \multicolumn{2}{|c|}{$22.3 \pm 0.5$} \\
\hline & $70.5 \pm 1.0$ & $67.5 \pm 1.8$ & $23.2 \pm 0.6$ & $20.6 \pm 0.4$ \\
\hline \multirow{2}{*}{ Weight (kg) } & \multicolumn{2}{|c|}{$56.1 \pm 1.7$} & \multicolumn{2}{|c|}{$58.8 \pm 1.3$} \\
\hline & $60.7 \pm 1.9$ & $50.5 \pm 1.6$ & $61.6 \pm 1.6$ & $53.8 \pm 1.0$ \\
\hline \multirow[t]{2}{*}{ BMI $\left(\mathrm{kg} / \mathrm{m}^{2}\right)$} & \multicolumn{2}{|c|}{$22.4 \pm 0.5$} & \multicolumn{2}{|c|}{$21.3 \pm 0.3^{*}$} \\
\hline & $23.2 \pm 0.6$ & $21.5 \pm 0.6$ & $21.4 \pm 0.4^{\star}$ & $21.0 \pm 0.5$ \\
\hline \multirow[t]{2}{*}{$\mathrm{PV}(\mathrm{ml} / \mathrm{kg})$} & \multicolumn{2}{|c|}{$43.6 \pm 1.3$} & \multicolumn{2}{|c|}{$47.6 \pm 6.8^{*}$} \\
\hline & $44.8 \pm 1.9$ & $42.2 \pm 1.9$ & $47.8 \pm 1.1$ & $47.2 \pm 1.1$ \\
\hline \multirow{2}{*}{$\mathrm{BV}(\mathrm{ml} / \mathrm{kg})$} & \multicolumn{2}{|c|}{$69.4 \pm 1.8$} & \multicolumn{2}{|c|}{$77.6 \pm 1.5^{\star}$} \\
\hline & $72.0 \pm 2.2$ & $66.3 \pm 2.8$ & $80.5 \pm 1.8^{\star}$ & $72.5 \pm 1.9^{\dagger}$ \\
\hline \multirow{2}{*}{$\dot{V}_{\mathrm{O}_{2 \text { peak }}}(\mathrm{ml} / \mathrm{kg} / \mathrm{min})$} & \multicolumn{2}{|c|}{$29.4 \pm 1.4$} & \multicolumn{2}{|c|}{$55.4 \pm 1.6^{\star}$} \\
\hline & $32.2 \pm 2.0$ & $26.0 \pm 1.4^{\dagger}$ & $59.7 \pm 1.6^{\star}$ & $47.6 \pm 1.7^{*}, \dagger$ \\
\hline \multirow[t]{2}{*}{$\mathrm{HR}_{\text {peak }}$ (beats/min) } & \multicolumn{2}{|c|}{$153.2 \pm 2.8$} & \multicolumn{2}{|c|}{$188.5 \pm 1.7^{*}$} \\
\hline & $153.2 \pm 3.8$ & $153.2 \pm 4.2$ & $191.3 \pm 1.6^{*}$ & $183.4 \pm 3.3^{\star}$ \\
\hline
\end{tabular}

Values are mean \pm SE of older $(n=22)$ and younger $(n=31)$ subjects. The means \pm SE of each gender in each age group are also shown. Older male $(n=12)$; older female $(n=10)$; younger male $(n=20)$; and younger female $(n=11)$. BMI, body mass index; $\mathrm{BV}$, blood volume; $\dot{V} \mathrm{O}_{2 \text { peak, }}$, peak oxygen consumption; and $\mathrm{HR}_{\text {peak }}$, heart rate at peak exercise. ${ }^{*}$ Indicates a significant difference $(p<0.05)$ between older and younger subjects, and ${ }^{\dagger}$ indicates a significant difference $(p<0.05)$ between the males and females within an age group. 
chairs for $60 \mathrm{~min}$ in a climatic chamber, where the room temperature was controlled at $25^{\circ} \mathrm{C}$ ( $\left.\mathrm{RH} 40 \%\right)$, to stabilize body fluid movement across the fluid compartments because of postural change. A 20-gauge catheter was inserted into an antecubital vein at $30 \mathrm{~min}$ of the resting period, and a control blood sample was drawn at the end of the rest period. A known amount $(\sim 15 \mathrm{mg})$ of Evans Blue dye (New World Corp., DeBary, FL) was then injected through the catheter, and blood samples were taken at 10 and $20 \mathrm{~min}$ after the injection. We measured the absorbance of the control plasma at 620 and $740 \mathrm{~nm}$ (UV 2200, Simadzu, Kyoto), and estimated the plasma blank absorbance (absorbance not because of Evans Blue) at $620 \mathrm{~nm}$ of the 10- and 20-min samples from the absorbance at $740 \mathrm{~nm}$ [17]. The equation to estimate the plasma blank absorbance at $620 \mathrm{~nm}$ from the plasma absorbance at $740 \mathrm{~nm}$ was

$$
\begin{gathered}
\mathrm{Abs}_{740 \mathrm{~nm}}=0.781 \times \mathrm{Abs}_{620 \mathrm{~nm}}-0.0177 \\
(r=0.99),
\end{gathered}
$$

where $A b_{740 \mathrm{~nm}}$ is the control plasma absorbance at $740 \mathrm{~nm}$, and $\mathrm{Abs}_{620 \mathrm{~nm}}$ is the absorbance of the control plasma at $620 \mathrm{~nm}$. The absorbance resulting from Evans Blue (corrected $\mathrm{Abs}_{620 \mathrm{~nm}}$ ) was calculated by subtracting the blank absorbance estimated with the equation from the measured $\mathrm{Abs}_{620 \mathrm{~nm}}$. Plasma volume was calculated from the corrected $\mathrm{Abs}_{620 \mathrm{~nm}}$ of the 10min sample and the amount of dye injected.

Hematocrit was determined in triplicate by the capillary centrifugation method. BV was calculated from plasma volume and hematocrit and corrected for 3\% trapped plasma and an F-cell ratio of 91\% [18].

To determine maximal aerobic capacity, we employed a semirecumbent cycling exercise protocol because this protocol is much safer for older people than a treadmill running rest. The peak oxygen uptake determined with this protocol $\left(\dot{V}_{2}\right.$ peak $)$ was used as an index of maximal aerobic capacity. The average oxygen uptake every $15 \mathrm{~s}$ was measured with a respiratory flow meter and gas analyzer (Aeromonitor AE260, Minato, Tokyo). Older subjects started pedaling at $20 \mathrm{~W}$ and the work rate was increased by $20 \mathrm{~W}$ every $2 \mathrm{~min}$. Younger subjects began pedaling at $59 \mathrm{~W}$, and the work rate was increased by $59 \mathrm{~W}$ (for male) or $30 \mathrm{~W}$ (for female) every 3 min until it reached $177 \mathrm{~W}$ (for male) or $118 \mathrm{~W}$ (for female). It was then increased $25 \mathrm{~W}$ every minute until the subjects were exhausted. The criteria for determining $\dot{V}_{2}$ peak were a respiratory exchange ratio $>1.1$ and a leveling off of $\dot{\mathrm{V}} \mathrm{O}_{2}$ with an increasing work load.

Data analyses and statistics. The values are shown as means \pm SE. Regression analysis was per-

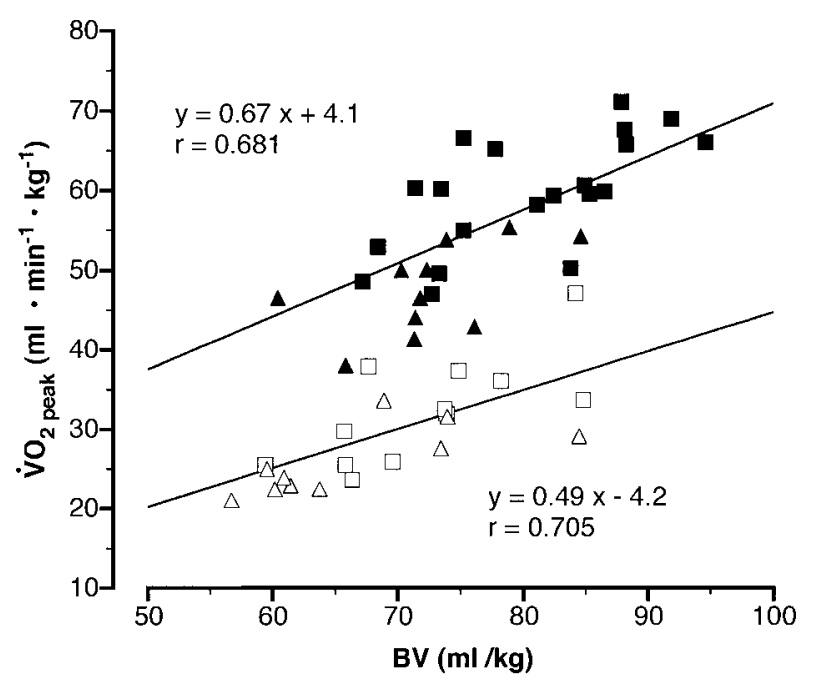

Fig. 1. The relationship between peak oxygen uptake $\left(\dot{V O}_{2 \text { peak }}\right)$ and blood volume (BV) in the older male ( $\square$; $n=12)$, older female $(\triangle ; n=10)$, younger male ( $\square ; n=20)$, and younger female subjects $(\Delta ; n=11)$. The regression equation and correlation coefficient for each age group was determined from the data for male and female subjects.

formed with the standard least square method. The difference in variables between the older and younger subjects was determined with Student's $t$-test. The effect of age on $\dot{\mathrm{O}}_{2 \text { peak }}$ at a given $\mathrm{BV}$ was determined by analysis of covariance (ANCOVA) with BV as a covariate. $p$ values $<0.05$ were considered significant.

\section{RESULTS}

The results of the present study showed that both $\dot{V}^{\mathrm{O}_{2} \text { peak }}$ and $\mathrm{BV}$ were significantly lower in the older subjects, compared with the younger subjects (Table 1). Body mass index (BMI) was slightly but significantly higher in the older subjects than in the younger ones. Heart rate at $\dot{V}_{2}$ peak $\left(\mathrm{HR}_{\text {peak }}\right)$ was lower in the older than in the younger subjects.

Figure 1 shows the relationship between $\dot{V}_{\mathrm{O}_{2} \text { peak }}$ and $\mathrm{BV}$ in the older and younger subjects. Because there was no significant gender effect in the regression parameters in either of the age groups, the data was pooled and represented by a single regression equation in each age group. The $\dot{V}_{\mathrm{O}_{2} \text { peak }}$ was linearly correlated with the BV for the older $(p<0.001)$ and younger $(p<0.001)$ subjects within the groups. Graphically, the regression line determined for the older subjects showed a downward shift. Statistical analysis by ANCOVA with BV as a covariate revealed that age had a significant effect on $\dot{V}_{2}$ peak at a given BV $(p<0.001)$.

Because the age-associated reduction in $\mathrm{HR}_{\text {peak }}$ has 


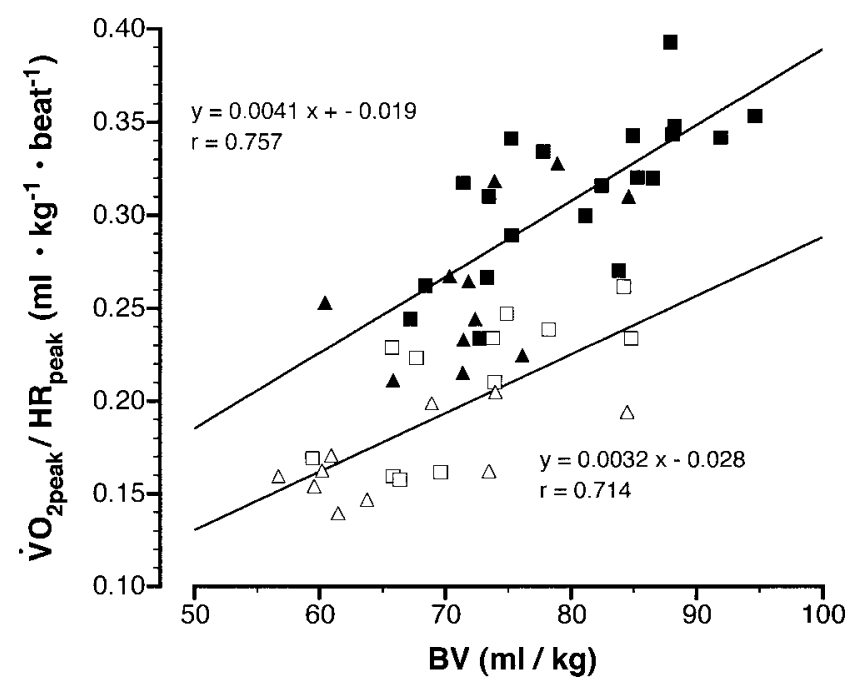

Fig. 2. The relationship between peak oxygen uptake per beat at peak exercise $\left(\dot{V}_{2}{ }_{\text {peak }} / \mathrm{HR}_{\text {peak }}\right)$ and blood volume (BV) in the older male $(\square ; n=12)$, older female $(\triangle$; $n=10)$, younger male $(\square ; n=20)$, and younger female subjects $(\boldsymbol{\Delta} ; \boldsymbol{n}=\mathbf{1 1})$. The regression equation and correlation coefficient for each age group was determined from the data for male and female subjects.

a direct influence on $\dot{V}_{2 \text { peak }}$, we calculated the $\dot{\mathrm{V}}_{2 \text { peak }}$ per heart beat $\left(\dot{V}_{\mathrm{O}_{\text {peak }}} / \mathrm{HR}_{\text {peak }}\right)$ to eliminate the effect of reduced $\mathrm{HR}_{\text {peak }}$ as a aging. Figure 2 shows the relationship between $\dot{V}_{\mathrm{O}_{2 \text { peak }}} / \mathrm{HR}_{\text {peak }}$ and $\mathrm{BV}$ in the older and younger subjects. The $\dot{V}_{2}$ peak $/ \mathrm{HR}_{\text {peak }}$ at any given $\mathrm{BV}$ was still lower in the older subjects than in the younger ones. The $\dot{V}_{2 \text { peak }} / \mathrm{HR}_{\text {peak }}$ at a given $\mathrm{BV}$ in the older subjects was significantly lower when the aging effect was analyzed by ANCOVA with BV as a covariate $(p<0.001)$.

\section{DISCUSSION}

The primary new finding of the present study was that the $\dot{V} \mathrm{O}_{2 \text { peak }}$ at any given $\mathrm{BV}$ was smaller in the older subjects than in the younger ones, i.e., graphically, the regression line determined in the older subjects was shifted downward, although the $\dot{V}_{2}$ peak was correlated with BV within both age groups. These results suggest that $\mathrm{BV}$ is an important determinant of $\dot{\mathrm{V}}_{2 \text { peak }}$ within the age groups, but that a factor or factors besides $\mathrm{BV}$ is also involved in the mechanism of the age-induced reduction in $\dot{\mathrm{V}}_{2 \max }$.

Jones et al. [10] reported that BV in physically active older females was preserved and that the relationship between $\dot{V}_{\mathrm{O}_{2} \max }$ and $\mathrm{BV}$ in older and younger women was represented by a single regression equation. The inconsistency in their results and ours might be due to the different characteristics of subjects examined, mainly, the mean age of the older subjects in the present study was 10 years older than the older subjects studied by Jones et al. [10]. Moreover, the maximal aerobic capacity of their older subjects was higher than ours. These differences might lead to different conclusions in their study and ours. However, the ranges of $\mathrm{BV}$ in the older and younger subjects in our study were wider than shown in their study. We assume that the relationships between $\dot{V}_{\mathrm{O}_{2 \text { peak }}}$ and $\mathrm{BV}$ in the relaively sedentary older ( $>65$ years) and also in the young adults should be better represented by the regression equation determined in our study because the relationship was determined with data comprising wider ranges of $\mathrm{BV}$.

It is known that cardiac output is linearly correlated with $\dot{V} \mathrm{O}_{2}$ during exercise $[19,20]$, and that maximal cardiac output is the determinant factor for $\dot{V}_{\mathrm{O}_{2}}$ max [21]. The decreased maximal HR with age must play a role in the reduction in $\dot{V}_{\mathrm{O}_{2} \max }[1,22,23]$. In the present study, the $\mathrm{HR}_{\text {peak }}$ was lower in the older subjects than in the younger ones. However, the corrected $\dot{V} \mathrm{O}_{2 \text { peak }}$ with $\mathrm{HR}_{\text {peak }}$ or $\dot{\mathrm{O}_{2} \text { peak }} / \mathrm{HR}_{\text {peak }}$ at any given $\mathrm{BV}$ in the older subjects was lower than in the younger ones, suggesting that the decreased $\mathrm{HR}_{\text {peak }}$ is not the only factor involved in the reduction in $\dot{\mathrm{V}}_{2 \text { peak }}$ at a given $\mathrm{BV}$ in the older subjects. Therefore, according to the Fick principal the age-related reduction in $\dot{V}_{\mathrm{O}_{2 \text { peak }}}$ at a given $\mathrm{BV}$ must be related to the reduced cardiac stroke volume and/or reduced capacity of muscle $\mathrm{O}_{2}$ extraction, besides the decrease in $\mathrm{HR}_{\text {peak }}$.

Cardiac stroke volume is represented by the difference of the end-diastolic ventricular volume and endsystolic ventricular volume. Because end-diastolic ventricular volume is influenced mainly by the venous return, BV is a determinant factor of stroke volume through an increase in venous return [12, 13, 24]. In the present study, the $\dot{V}_{\mathrm{O}_{2 \text { peak }}}$ was linearly correlated with BV within the groups, suggesting that the FrankStarling mechanism is preserved in older subjects [25-27]. However, the $\dot{V}_{2 \text { peak }}$ and $\dot{V}_{\mathrm{O}_{\text {peak }}} / \mathrm{HR}_{\text {peak }}$ at any given $\mathrm{BV}$ was smaller in the older subjects, suggesting that the stroke volume at a given BV could be smaller in older individuals. The end-diastolic ventricular volume in older people has been reported to be similar or even larger during exercise in comparison with younger subjects [24-26]. It also has been reported that the exercise-induced increase in the ejection fraction at peak exercise was attenuated in older people $[24,26,28]$. Taken together, we assume that stroke volume at a given BV is smaller in older people because of the decreased ejection fraction. The cause of decreased ejection fraction might be a result of an age-related reduction in the response to $\beta$-adrenergic stimulation or larger afterload as a result of higher ar- 
Aging and $\dot{V}_{\mathrm{O}_{2} \text { peak }}-\mathrm{BV}$ Relationship

terial pressure during exericse in older people, though we did not measure arterial pressure during exercise $[23,25]$.

A reduced skeletal muscle mass, or a reduced oxygen extraction capacity, with age is a possible factor for the shifted regression line for the relationship between $\dot{V}_{\mathrm{O}_{2} \text { peak }}$ and $\mathrm{BV}$ in the older subjects $[25,29]$. Proctor and Joyner [29] reported that $\dot{V}_{2}$ peak was correlated with skeletal muscle mass within the age groups, and the regression line for the older subjects was shifted downward. They concluded that the reduced aerobic capacity per kilogram of muscle very likely results from age-associated reductions in maximal cardiac output and/or muscle blood flow. In the present study, the BMI for the older subjects was larger than that for the younger subjects, suggesting that the muscle (fat-free) mass per body weight was smaller in the older subjects. We did not actually measure body composition in the present study. However, even if the \% body fat is $20 \%$ in the younger subjects and $30 \%$ in the older subjects, the calculated regression line for the relationship between $\dot{V}_{\mathrm{O}_{2} \text { peak }}$ and $\mathrm{BV}$ normalized by assumed fat-free mass was still shifted downward in the older subjects. Therefore the reduced $\mathrm{CO}_{\text {peak }}$, a result of reduced stroke volume besides the decreased $\mathrm{HR}_{\text {peak }}$, which is a consequence of diminished cardiac muscle contractility, is most likely involved in the reduction of $\dot{\mathrm{V}}_{2 \text { peak }}$ with aging at a given $\mathrm{BV}$.

In summary, we confirmed that $\dot{V}_{2 \text { max }}$ is correlated with $\mathrm{BV}$ in older and young adults, suggesting that $\mathrm{BV}$ is a major factor in the determination of $\dot{\mathrm{V}}_{2 \text { peak }}$ within the age groups. At any given $\mathrm{BV}$, however, the $\dot{V}_{2}$ peak was lower in older adults than in young ones. Data analysis suggested that a factor, or factors, other than BV, HR, or muscle mass is also involved in the mechanism of the reduction in the age-associated decrease in $\dot{\mathrm{V}}_{2 \max }$ besides these factors.

This study was supported in part by grants from the Foundation of Osaka Gas Group, the Foundation of Total Health Promotion, and the Ministry of Education, Science, Sports, and Culture, Japan.

\section{REFERENCES}

1. Mazzeo RS, Cavanagh P, Evans WJ, Fiatarone M, Hagberg J, McAuley E, and Startzell J: ACSM Position Stand on Exercise and Physical Activity for Older Adults. Med Sci Sports Exerc 30: 992-1008, 1998

2. Åstrand I, Åstrand P-O, Hallback I, and Kilbom A: Reduction in maximal oxygen uptake with age. J Appl Physiol 35: 649-654, 1973

3. Buskirk ER and Hodgson JL: Age and aerobic power: the rate of change in men and women. Fed Proc 46:
1824-1829, 1987

4. Dehn MM and Bruce RA: Longitudinal variations in maximal oxygen intake with age and activity. J Appl Physiol 33: 805-807, 1972

5. Fitzgerald MD, Tanaka H, Tran ZV, and Seals DR: Agerelated declines in maximal aerobic capacity in regularly exercising vs. sedentary women: a meta-analysis. J Appl Physiol 83: 160-165, 1997

6. Pollock ML, Mengelkoch LJ, Graves JE, Lowenthal DT, Limacher MC, Foster C, and Wilmore JH: Twenty-year follow-up of aerobic power and body composition of older track athletes. J Appl Physiol 82: 1508-1516, 1997

7. Convertino VA: Blood volume: its adaptation to endurance training. Med Sci Sports Exerc 23: 1338-1348, 1991

8. Convertino VA and Ludwig DA: Validity of $\dot{V}_{\mathrm{O}_{2 m a x}}$ in predicting blood volume: implications for the effect of fitness on aging. Am J Physiol Regul Integr Comp Physiol 279: R1068-R1075, 2000

9. Davy $\mathrm{K}$ and Seals DR: Total blood volume in healthy young and older men. J Appl Physiol 76: 2059-2062, 1994

10. Jones PP, Davy KP, DeSouza CA, Van Pelt RE, and Seals DR: Absence of age-related decline in total blood volume in physically active females. Am J Physiol 272 (Heart Circ Physiol) 41: H2543-H2540, 1997

11. Convertino VA: Cardiovascular consequences of bed rest: effect on maximal oxygen uptake. Med Sci Sports Exerc 29: 191-196, 1997

12. Hopper MK, Coggan AR, and Coyle EF: Exercise stroke volume relative to plasma-volume expansion. $J$ Appl Physiol 64: 404-408, 1988

13. Krip B, Gledhill N, Jamnik V, and Warburton D: Effect of alterations in blood volume on cardiac function during maximal exercise. Med Sci Sports Exerc 29: 14691476, 1997

14. Lindeman RD: Renal and urinary tract function. In: Handbook of Physiology, Section 11: Aging, ed. Masoro EJ, Oxford University Press, New York, pp 485-504, 1995

15. Stevenson ET, Davy KP, and Seals DR: Maximal aerobic capacity and total blood volume in highly trained middle-aged and older female endurance athletes. J Appl Physiol 77: 1691-1696, 1994

16. Fortney SM, Turner C, Steinmann L, Driscoll T, and Alfrey C: Blood volume response of men and women to bed rest. J Clin Pharmacol 34: 434-439, 1994

17. Foldager $\mathrm{N}$ and Blomqvist CG: Repeated plasma volume determination with the Evans Blue dye dilution technique: the method and a computer program. Comput Biol Med 21: 35-41, 1991

18. Greenleaf JE, Convertino VA, and Mangseth GR: Plasma volume during stress in man: osmolality and red cell volume. J Appl Physiol 47: 1031-1038 1979

19. Makrides L, Heigenhauser GJF, and Jones NL: High-intensity endurance training in 20- to 30- and 60- to 70yr-old healthy men. J Appl Physiol 69: 1792-1798, 1990

20. Minson CT and Kenney WL: Age and cardiac output during cycle exercise in thermoneutral and warm environments. Med Sci Sports Exerc 29: 75-81, 1997 
21. Rowell LB: Circulatory adjustment to dynamic exercise. In: Human Circulation Regulation during Physical Stress, Oxford University Press, New York, pp 213-256, 1986

22. Fuchi T, Iwaoka K, Higuchi M, and Kobayashi S: Cardiovascular changes associated with decreased aerobic capacity and aging in long-distance runners. Eur J Appl Physiol 58: 884-889, 1989

23. Fleg JL: Alterations in cardiovascular structure and function with advancing age. Am J Cardiol 57: 33C44C, 1986

24. Dempsey JA and Seals DR: Aging, exercise, and cardiopulmonary function. In: Perspectives in Exercise Science and Sports Medicine, Vol. 8, Exercise in Older Adults, Cooper Publishing Group, Carmel, pp 237304, 1993
25. Lakatta EG: Cardiovascular regulatory mechanisms in advanced age. Physiol Rev 73: 413-467, 1993

26. Lakatta EG: Cardiovascular system. In: Handbook of Physiology, Section 11: Aging, ed. Masoro EJ, Oxford University Press, New York, pp 413-474, 1995

27. Hagberg JM, Goldberg AP, Lakatta L, O'Connor FC, Becker LC, Lakatta EG, and Fleg JL: Expanded blood volumes contribute to the increased cardiovascular performance of endurance-trained older men. J Appl Physiol 85: 484-489, 1998

28. Port S, Cobb FR, Coleman RE, and Jones RH: Effect of age on the response of the left ventricular ejection fraction to exercise. N Engl J Med 303: 1133-1137, 1990

29. Proctor DN and Joyner MJ: Skeletal muscle mass and the reduction of $\dot{V}_{2 \text { max }}$ in trained older subjects. J Appl Physiol 82: 1411-1415, 1997 